\title{
HERANÇA DA PIGMENTAÇÃO COM ANTOCIANINA EM CROTALARIA JUNCEA L. (1)
}

\author{
MANOEL ALBINO COELHO DE MIRANDA (2.4), EDUARDO ANTONIO BULISANI $(2,4)$, \\ JOÁO PAULO FEIJÄO TEIXEIRA $(3,4)$ E HIPÓLITO ASSUNÇĀO \\ ANTONIO MASCARENHAS $(2,4)$
}

\begin{abstract}
RESUMO
Com a finalidade de obter informaçōes sobre genes marcadores, foram hibridadas, manualmente, linhagens de crotalária contrastantes em relação à cor no hipocótilo, na base das asas das flores e das sementes. As sementes das gerações paternais, de $F_{1}, F_{2}$ e do retrocruzamento para o pai recessivo, foram semeadas em casa de vegetação para o estudo da segregação. Verificou-se que a presença é dominante em relação à ausência de pigmentação com antocianina, que a herança deste caráter é monogênica e que há efeito pleiotrópico entre sementes pigmentadas, pinta púrpura na base das asas das flores e hipocótilo roxo. Aventou-se a existência de polimeria na geração $F_{2}$, uma vez que dentro das plantas com sementes pigmentadas foi possivel a separação das șementes em cinco classes de intensidade de coloraçāo. Sugeriu-se o símbolo Aa - para presença e aa aa - para ausência de pigmentação como discriminante do referido lócus.
\end{abstract}

Termos de indexação: crotalária, herança da pigmentação com antocianina, pleiotropia.

(1) Trabaiho financiado parcialmente pela Companhia Industrial de Papel Pirahy. Recebido para publicação em 10 de dezembro de 1988 e aceito em 5 de maio de 1989.

(2) Seção de Leguminosas, Instituto Agronômico (IAC), Caixa Postal 28, 13001 Campinas (SP).

(3) Seção de Fitoquímica, IAC.

(4) Com bolsa de pesquisa do CNPq. 


\section{INTRODUÇÃO}

A crotalária é a principal leguminosa para a produção de celulose de alta qualidade para o fabrico de papéis, tendo ainda participação importante na biofertilizaçāo como nova alternativa para plantio direto na entressafra de outono-inverno (BULISANI \& BRAGA, 1985, e BULISANI et al., 1987).

Os programas de melhoramento desenvolvidos no IAC foram eficientes na criação de linhagens e cultivares resistentes à murcha causada por Ceratocystis fimbriata (RIBEIRO et al., 1977; MIRANDA et al., 1984, e SALGADO et al., 1986). Esse foi um dos principais problemas da cultura, sendo superado com $O$ lançamento do cultivar IAC-1, que hoje ocupa mais de $70 \%$ da área cultivada em São Paulo (4.700ha). Entretanto, a baixa produção de sementes ainda é um dos entraves à utilização da crotalária em larga escala, pois encarece em demasia o preço deste insumo. Dois fatores principais são responsáveis pela má fertilizaçāo das flores: a necessidade de polinização entọmófila e os mecanismos que previnem a autofecundação.

A flor da crotalária mostra adaptação à polinização entomófila, com quilha rígida que, quando pressionada, expóe o estigma a ser polinizado. No momento em que ele é exposto, pela pressão do inseto, este empurra o pólen acumulado na extremidade superior da quilha como se fosse um êmbolo, aderindo ao inseto polinizador. Por essa razão é que somente himenópteros de certo porte, como as mamangavas (Bombus), conseguem polinizar eficientemente a crotalária (MIRANDA, 1981).

A protandria, maturação do pólen antes de o estigma estar receptivo, também é encontrada nesta leguminosa (VERNA \& SHRIVAS, 1968). Mas o mecanismo mais eficiente para evitar a endogamia é a incompatibilidade, pois os gametas só são funcionais quando utilizados em cruzamentos. O sistema de incompatibilidade encontrado em crotalária é o homomorfo gametofítico (MIRANDA, 1981). Neste sistema, a incompatibilidade é determinada pela própria constituiçāo genética do pólen, sendo controlada por um só lócus, apresentando grande número de formas alélicas. No sistema gametofítico, existem três tipos básicos de polinização: com incompatibilidade completa, quando ambos os alelos são comuns; em que metade dos grãos de pólen é compatível, quando um dos alelos é diferente; e em que todo o pólen é compativel, quando ambos os alelos são diferentes (LEWIS, 1954).

Diante do crescente interesse pela cultura, a Seção de Leguminosas vem estudando a possibilidade de utilizar genes marcadores que possibilitarão o controle da polinização entomófila e manual, permitindo agilitar o processo de melhoramento genético, com o intuito de se chegar à produçāo de híbridos. 
Como a polinização entomófila não obedece à distribuição previsivel no campo, as plantas fornecedoras de pólen e as receptoras terão que ser misturadas ao acaso; necessita-se, então, de características diferenciais que possibilitem a separação porterior das sementes por processos físicos, especialmente os óti$\cos$ (Seletron).

A autocompatibilidade é uma característica dominante (MIRANDA, 1981, e COSTA \& AMARAL, 1976), que, aliada à heterose, poderá solucionar o problema de produçāo de sementes. Para tanto, há necessidade de se conhecer a herança da pigmentação das sementes, pois pretende-se misturar linhas auto compativeis coloridas com linhas incompativeis sem pigmentação, para a obtenção do híbrido.

Caso haja um aumento significativo na produtividade de sementes através de hibridos, poderá tornar-se econômica até a extração de galactomananas das sementes, pois estas apresentam cerca de 15\% dessa importante goma (MILLER, 1967). Entretanto, determinaçōes preliminares obtidas pela Seção de Fitoquímica do IAC apontam para valores entre 7 e 8,5\%, o que, pelo menos, indica variabilidade para essa característica em diferentes genótipos.

\section{MATERIAL E MÉTODOS}

Como material de sementes pigmentadas, utilizou-se a linhagem IAC772 , uma das componentes do cultivar $\mid A C-1$, sendo produto de seis autofecundaçōes e, portanto, com alto grau de homozigose. Como material sem pigmentação, empregou-se a linhagem $\mid \mathrm{AC}-2$, obtida por sucessivos cruzamentos entre irmäos germanos, dada a impossibilidade de autofecundaçăo, portanto também com alto grau de endogamia.

A hibridação, realizada em casa de vegetação entre dez plantas de cada uma das linhagens, foi obtida pela emasculação manual dos botões, pela retirada do estandarte, das asas, da quilha e das anteras, deixando o estigma exposto. Em seguida, o pólen da planta polinizadora foi colocado sobre o gineceu. Essa operaçāo é facilitada, pois a quilha, sendo rigida, permite que o pólen ai seja armazenado durante o processo de fertilização. Utilizou-se a linhagem IAC-2 como receptora de pólen e a IAC77-2, como fornecedora. As mil e duzentas sementes $F_{2}$ foram obtidas pela autofecundação natural de doze plantas $F_{1}$ (cem sementes por planta), pois a autocompatibilidade é dominante em relação à incompatibilidade (MIRANDA, 1981). Realizou-se o cruzamento teste, cruzando as plantas $F_{1}$ com a linhagem IAC-2, agora utilizada como doadora de pólen, pelo método acima descrito.

Efetuou-se a avaliação em casa de vegetação onde havia as geraçōes patemais, a $F_{1}$, a $F_{2}$ e o retrocruzamento para o pai recessivo, cruzamento teste, semeados em vasos plásticos, preenchidos com terra. Em cada vaso, semearam-se 
cinco sementes, sendo 240 para a geração $F_{2}$ e quinze para o cruzamento teste, e dez vasos para cada uma das demais geraçōes. A presença de pigmentação no hipocótilo das plântulas na altura do solo foi determinada quatro dias depois da emergência; na base das asas das flores, 60 dias após a germinação e, nas sementes na maturação, decorridos 130 dias da semeadura. Para determinação de provável efeito pleiotrópico, após o prótocolo quanto à coloraçāo do hipocótilo, as plantas sem pigmentação foram aneladas com plástico para futura discriminação.

Os desvios em relação à proporção esperada foram analisados pelo teste do qui quadrado (GOMES, 1970).

Para evitar a morte de plantas por patógenos de solo, os vasos foram irrigados com uma suspensão de benomil (Benlate), $2 \mathrm{~g}$ por litro de água aos $20 \mathrm{e}$ 60 dias da semeadura.

\section{RESULTADOS E DISCUSSÃO}

A linhagem IAC77-2 apresentou sementes de coloração preta, com flores que mostravam pinta púrpura na base das asas e hipocótilo roxo. A linhagem IAC-2, nas mesmas condições, exibiu coloração creme nas sementes, asas totalmente amarelas e hipocótilo verde, sem pigmentação. A geração $F_{1}$ mostrou-se uniforme com hipocótilo roxo, asas com pinta púrpura na base e sementes com coloração próxima ao preto (Figura 1).

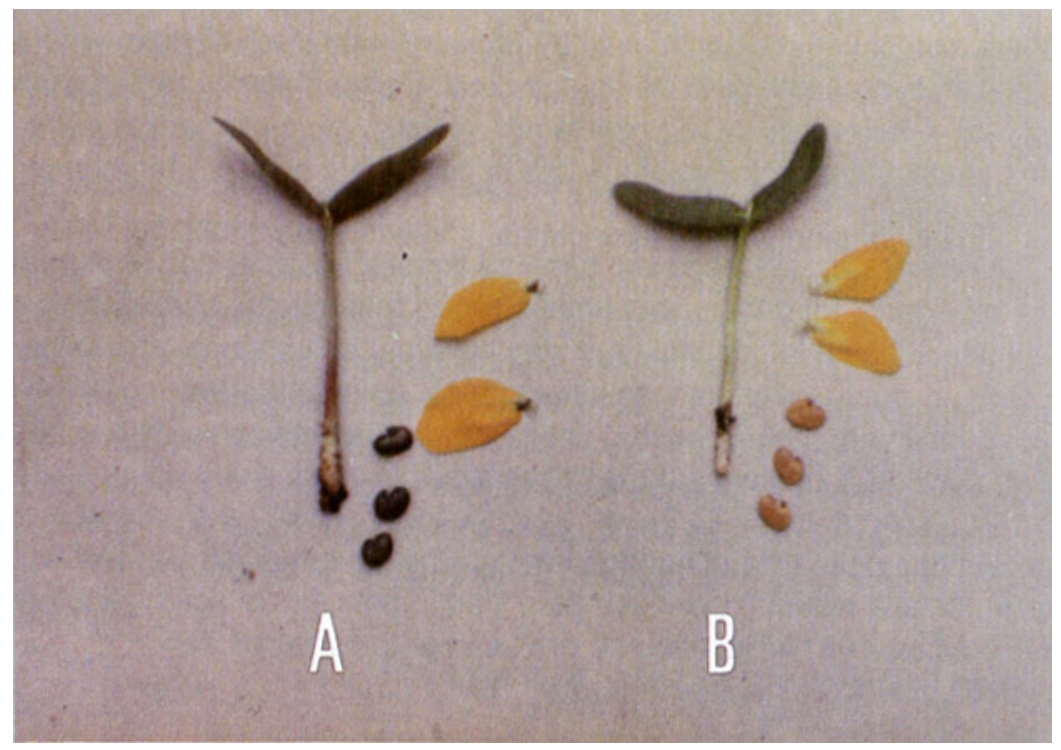

FIGURA 1. A: Presença (IAC77-2) e B: ausência (IAC-2) de pigmentação nas sementes, no hipocótilo e na base das asas das flores. 
Na geração $F_{2}$ - Quadro 1 - das 1.105 plantas analisadas, 833 apresentaram hipocótilo roxo e 272 , verde, não se verificando desvios significativos em relação à proporção esperada: isso pressupōe uma segregação monofatorial, sendo a pigmentação dominante sobre a ausência de coloração. No cruz̧amento teste, em que se tem a segregação gônica espelhada na segregação zigótica, obtiveram-se 57 plantas com hipocótilo verde para 46 plantas com hipocótilo roxo, também com desvios não-significativos, o que confirma o resultado anterior, obtido na geração $F_{2}$ (Quadro 1).

QUADRO 1. Frequêencia observada e esperada e valores de $\chi^{2}$ para coloração de hipocótilo, na geração $F_{2}$ e no cruzamento teste

\begin{tabular}{|c|c|c|c|c|c|c|}
\hline & \multicolumn{2}{|c|}{$\begin{array}{l}\text { GERAÇÃO } F_{2} \\
\text { Fenótipo }\end{array}$} & & \multicolumn{3}{|c|}{$\begin{array}{c}\text { CRUZAMENTO TESTE } \\
\text { Fenótipo }\end{array}$} \\
\hline & Roxo & Verde & & Roxo & Verde & \\
\hline F. observada & 833,00 & $.272,00$ & & 46,00 & 57,00 & \\
\hline F. esperada & 828,75 & 276,25 & & 51,50 & 51,50 & \\
\hline$\chi^{2}$ & 0,03 & 0,07 & $0,10 \mathrm{~ns}$ & 0,59 & 0,59 & $1,18 \mathrm{~ns}$ \\
\hline
\end{tabular}

Nível de significância $5 \%$.

As plantas com hipocótilo sem pigmentação resultaram sempre em plantas que produziram sementes creme e flores sem pinta púrpura. Fato semeIhante foi verificado quando da presença de hipocótilo roxo, cujas plantas sempre produziram sementes de coloraçāo preta a levemente avermelhada e sempre com pinta roxa na base das asas das flores, mostrando efeito pleiotrópico quanto à presença de antocianina nessas partes das plantas.

A variação na intensidade de cor do tegumento das sementes da geração $F_{2}$ pode ser decorrente de polimeria, sendo possivel a identificação de seis classes fenotípicas (Figura 2) 


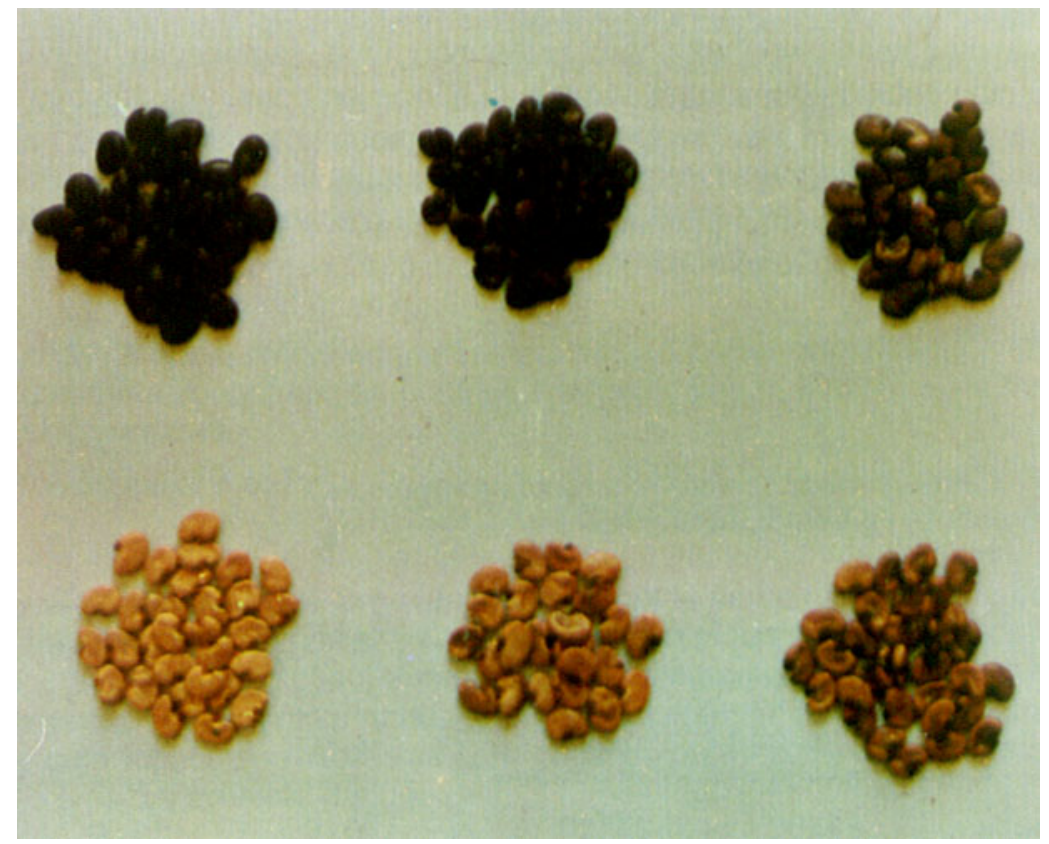

FIGURA 2. Classes de coloração de, sementes verificadas na geração $F_{2}$

Caso houvesse somente polimeria em que se supōe efeito genético igual e cumulativo e sem dominância, na geração $F_{2}$, para'dois genes, teriamos cinco classes de freqüência fenotípica possiveis. Entretanto, as proporçōes verificadas na geração $F_{2}$ e no retrocruzamento não suportam a hipótese aventada. Poder-se-ia sugerir então a existência de interação não alélica, epistase recessiva, na qual não haveria a presença de antocianina quando determinado cromógeno estivesse em homozigose recessiva. Agora, admitindo que cada cromógeno tivesse efeito polimérico, haveria cinco classes de freqüência fenotípica. Está segunda hipótese concorda com as segregaçōes obtidas, levando-se em consideração a presença e a ausência de antocianina. Entretanto, detectaram-se seis classes na geração $F_{2}$. Portanto, não se pôde esclarecer a possivel polimeria condicionada à variaçāo da intensidade de cor do tegumento da semente.

Sugere-se a símbolo $\mathrm{Aa}$ - para a presença de pigmentação, e aa aa para a ausência de pigmentaçāo com antocianina para caracterizaçāo do lócus. 


\title{
INHERITANCE OF ANTHOCYANIN PIGMENTATION IN CROTALARIA JUNCEA L.
}

\begin{abstract}
SUMMARY
In order to obtain information about gene markers, crosses were made between contrasting lines in relation to the pigmentation of hipocotyl, base of the flower wing and seed coat. Paternal, $F_{1}, F_{2}$ generations and backcross to recessive female parent were cultivated in the greenhouse. The inheritance was monogenic. The presence of anthocyanin pigment was dominant in relation to the absence. There was a pleiotropic effect among pigmented seed, purple stain at the base of the flower wing and purple hipocotyl. It was possible to separate five classes of pigmentation intensity among the plants with colored seeds, indicating the possibility of occurrence of polymeria in the $F_{2}$ generation. A symbol $A a$ - was suggested for the presence and aa aa - for the absence of anthocyanin pigment to discriminate the locus.
\end{abstract}

Index terms: sunn-hemp, inheritance of anthocyanin pigmentation, pleiotropy.

\section{AGRADECIMENTOS}

Agradecemos aos Técnicos Agropecuários Aparecido da Silva e Valdeir Biudes Hermoso a dedicação e entusiasmo na realização do trabalho.

\section{REFERÊNCIAS BIBLIOGRÁFICAS}

BULISANI, E.A. \& BRAGA, N.R. Potencialidade para utilização de leguminosas como cobertura vegetal de inverno no Estado de São Paulo. In: FANCELLI, A.L.,coord. Atualização em plantio direto. Campinas, Fundaçāo Cargill, 1985. p.223-235.

em sistemas de adubação verde ou rotação de culturas. In: FANCELLI, A.L., coord. Plantio direto. Piracicaba, FEALQ/ESALQ/USP, 1987. p.61-70.

COSTA J.D. \& AMARAL, E. Produção de sementes de Crotalaria juncea L. na presença e ausência de insetos polinizadores. Revista de Agricultura, Piracicaba, 51(2):57-60, 1976.

GOMES, F.P. Curso de estatística experimental. 4.ed. Piracicaba, Nobel, 1970. 430p.

LEWIS, D. Comparative incompatibility in angiosperms and fungi. Advances in Genetics, 6:637-647, 1954.

MILLER, R.H. Crotalaria seed morphology, anatomy and identification. United States, Department of Agriculture. Agricultural Research, 1967. 73p. (Technical Bulletin, 1373) 
MIRANDA, M.A.C. de. Sisterna de incompatibilidade e autocompatibilidade em Crotalaria juncea $L$. Piracicaba, Escola Superior de Agricultura "Luiz de Queiroz", 1981, 40p. Dissertação (Mestrado)

; BULISANI, E.A.; BRAGA, N.R.; GALLO, P.B.; SALGADO, A.L. \& RIBEIRO, I.J.A. Cultivar IAC-1 de Crotalaria juncea L. Comunicação da Pesquisa Agropecuária, São Paulo, 2(4):7, 1984.

RIBEIRO, I.J.A.; MIRANDA, M.A.C. de; BULISANI, E.A.; ALMEIDA, L.D'A.; LOVADINI, L.A.C.; SUGIMORI, M.H. \& PARADELA FILHO, O. Melhoramento da crotalária: I. Autocompatibilidade e resistência à murcha de Ceratocystis fimbriata. Bragantia, Campinas, 36:291-295, 1977.

SALGADO, A.L.B.; CIARAMELLO, D. \& AZZINI, A. Cultivar IAC-KR.1, Comunicação da Pesquisa Agropecuária, São Paulo, 2(5):14, 1984.

VERNA, S.N.P. \& SHRIVAS, S.R. Study of anthesis in sunn-hemp (Crotalaria juncea L.). Jwaharlal Nehru Krishi Wishwua Vidyalaya, Research Journal, Jabalpur, 2:34-37, 1968. 